\title{
ABORDAGENS METODOLÓGICAS NO CAMPO DA DINÂMICA DE USO E COBERTURA DE TERRA: UM OLHAR PARA A REALIDADE MOÇAMBICANA
}

\author{
Lucrêncio Silvestre MACARRINGUE ${ }^{1}$ \\ Édson Luis BOLFE² \\ Óscar Alexandre FUMO3
}

\begin{abstract}
Resumo
O objetivo desta revisão é discutir o enquadramento do estudo da dinâmica de uso e cobertura da terra nas abordagens metodológicas conhecidas, com olhar para a realidade moçambicana, que se distingue de outras no que diz respeito às práticas culturais, questões políticas e financeiras e conhecimento tecnológico no ordenamento do território. Esta revisão debate sobre que caminhos percorrer para um efetivo levantamento do uso e cobertura de terra com base nas abordagens metodológicas dominantes no campo científico tendo em conta as particularidades de Moçambique. Com base no levantamento teórico sobre as abordagens metodológicas e questões inerentes à dinâmica de uso e cobertura de terra, descrição das atividades envolvidas no âmbito do levantamento de uso e cobertura de terra, foi possível estabelecer relações que permitem enquadrar cada atividade em uma dada abordagem metodológica. O estudo permitiu visualizar diferentes possibilidades metodológicas para a condução de uma pesquisa sobre a dinâmica do uso e cobertura da terra em Moçambique.
\end{abstract}

Palavras-chave: Métodos de pesquisa. Paisagem. Uso e cobertura de terra.

\section{METHODOLOGICAL APPROACHES FOR LAND USE AND LAND COVER DYNAMICS STUDIES: A LOOK AT THE MOZAMBICAN REALITY}

\begin{abstract}
This review aims to discuss the framework of the study of land use and land cover dynamics into the widely disseminated methodological approaches, with a look at the Mozambican reality, which differs from others with respect to cultural practices, political, financial and Know how issues around the land use planning. This review discusses about which paths to follow for an effective survey of land use and land cover based on the known methodological approaches in the scientific and academicals environment. Based on the theoretical survey on methodological approaches and issues inherent to the

\footnotetext{
${ }_{1}^{1}$ Doutorando em Geografia pela Universidade Estadual de Campinas, UNICAMP. E-mail: lusimac@gmail.com

2 Pesquisador em Geoprocessamento e Sensoriamento Remoto na Empresa Brasileira de Pesquisa Agropecuária. E-mail: edson.bolfe@embrapa.br

3 Mestrando em Linguística Aplicada pela Universidade Estadual de Campinas, UNICAMP. Email: oscarfumo@gmail.com
} 
dynamics of land use and land cover, description of the activities involved in the land use and land cover survey, it was possible to establish relationships among them that allow framing each activity to the methodological approach. The research allowed to visualize different methodological possibilities for conducting research on the dynamics of land use and land cover in Mozambique.

Keywords: Research methods. Landscape. Land use and land cover.

\section{ENFOQUES METODOLÓGICOS EN EL CAMPO DE LA DINÁMICA DE USO Y LA COBERTURA DEL SUELO: UNA MIRADA A LA REALIDAD MOZAMBIQUEÑA}

\section{Resumen}

Esta revisión tiene como objetivo discutir el marco del estudio de la dinámica del uso y cobertura del suelo basado en los enfoques metodológicos conocidos, con una mirada a la realidad mozambiqueña, que se difiere de otras con respecto a las prácticas culturales y políticas, conocimiento tecnológico y recursos financieros en la organización de territorio. Esta revisión hace posible debatir sobre qué caminos tomar para una encuesta efectiva del uso y cobertura del suelo basada en los enfoques metodológicos dominantes en el campo científico. Sobre la base de la encuesta teórica sobre enfoques metodológicos y cuestiones inherentes a la dinámica del uso y cobertura del suelo, la descripción de las actividades involucradas en la encuesta del uso y cobertura del suelo, fue posible establecer relaciones entre ellos que permitan enmarcar cada actividad al enfoque metodológico. La investigación permitió visualizar diferentes posibilidades metodológicas para realizar estudios sobre la dinámica del uso y cobertura del suelo en Mozambique.

Palabras clave: Métodos de investigación. Paisaje. Uso y cobertura del suelo.

\section{INTRODUÇÃO}

A busca pelo conhecimento é uma que acompanha o Homem desde os primórdios da sua existência. O conhecimento é adquirido por meio de técnicas e processos que, no campo científico, têm a designação de abordagens metodológicas.

Embora haja diferentes concepções sobre o que seria metodologia, há de comum em todos conceitos o que Hegenberg (1976) designa método científico, cujo objetivo é o aperfeiçoamento dos procedimentos e critérios utilizados na pesquisa. O método é aqui entendido como sendo o caminho para a concretização de determinado fim ou propósito. 
O desenvolvimento de uma pesquisa é um processo de diversas etapas, desde a concepção do tema até a divulgação dos resultados. Todo esse percurso depende da metodologia seguida e do método escolhido. Isso pressupõe um planejamento antecipado.

Existem diversas abordagens metodológicas para o desenvolvimento pleno de uma pesquisa, sendo que é responsabilidade do pesquisador escolher a que mais se adequa aos seus interesses de pesquisa. Theóphilos e Ludícibus (2001) sugerem a categorização das abordagens metodológicas em “convencionais" e “não-convencionais". Nas convencionais, incorpora-se a empiricista (representada principalmente por Bacon, Locke, Mill e Hume, da Escola Inglesa), a positivista (associada às ideias de Auguste Comte), a sistémica (associada à teoria geral dos sistemas, elaborada por Bertalanffy), e a estruturalista (fundamentada no linguista Ferdinand Saussure e no antropólogo Lévi-Strauss). Nas abordagens não-convencionais, podem ser encontradas as seguintes subcategorias: a fenomenológica (baseada em Edmund Husserl (1859-1938)), dialética (com forte contribuição de Hegel). A partir dessas abordagens se chega ao que se designa pesquisas qualitativas, quantitativas, etnográficas e quali-quantitativas.

Estudos de referência sobre a cobertura de terra em Moçambique têm sido realizados por consultores contratados pelo governo e os demais (estudos), por pesquisadores individuais, no geral como resultados de dissertações e teses. Em razão disso, os percursos metodológicos aplicados à realização dos estudos são diversos, tanto quanto são os pesquisadores, as suas vinculações científicas e os interesses associados à pesquisa. Chama à atenção, no entanto, que, em muitos casos, os pesquisadores adoptam e aplicam metodologias de forma isolada, a despeito da complexidade do contexto moçambicano, que envolve diversas "variáveis" ou factores cuja captação implica combinações e/ou ajustamentos de procedimentos metodológicos.

Partindo dessas constatações e do pressuposto de que o contexto moçambicano levanta questões metodológicas complexas, propõe-se, nesta revisão, discutir as diversas abordagens metodológicas, seu papel no desenvolvimento de estudos sobre a paisagem (no âmbito geográfico), na componente de uso e cobertura de terra afim de uma melhor orientação na 
condução dos estudos desta natureza. Este ensaio constitui uma base de debate para o aprimoramento dos métodos de pesquisa para o desenvolvimento científico nesta área, principalmente em países com baixa produção científica, como o caso de Moçambique, no continente africano.

\section{PESQUISA QUALITATIVA, QUANTITATIVA E ETNOGRÁFICA}

Em qualquer pesquisa, é inevitável o questionamento sobre o método que se deve seguir, suas características, papel do pesquisador, estratégias de coleta de dados, enfim, um arcabouço para o alcance dos resultados desejados.

Uma pesquisa qualitativa pode ser, no seu sentido mais amplo, entendida como uma metodologia que produz seus dados fundamentalmente através da observação in loco de pessoas, fenômenos e lugares, com os quais o pesquisador estabelece uma interação direta para sua compreensão. Segundo Godoy (1995), esta perspectiva de pesquisa pode apresentar três tipos de procedimentos: pesquisa documental, estudo de caso e etnografia.

Entende-se como pesquisa documental aquela que busca informações em documentos primários, ou seja, que não receberam nenhuma interpretação científica: relatórios, reportagens de jornais, revistas, cartas, filmes, gravações, fotografias, entre outras matérias de divulgação (OLIVEIRA, 2007). Ela possibilita ampliar o entendimento de fenômenos e objetos que se podem compreender por meio de uma contextualização histórica e/ou sociocultural (SÁ-SILVA et al., 2009).

O Estudo de caso é recomendado na compreensão dos fenômenos sociais mais complexos, dado o fato de preservar as características holísticas e significativas dos eventos da vida real (YIN, 2005). Corresponde a uma história de um fenômeno quer passado ou atual, elaborada por meio de múltiplas fontes, desde dados da observação direta e entrevistas sistemáticas, até pesquisas em arquivos públicos e privados (VOSS et al., 2002; FREITAS; JABBOUR, 2011).

A pesquisa etnográfica busca descrever uma cultura ou grupo com recurso à investigação naturalista, observacional, descritiva, contextual, não limitada e em profundidade, com maior rigor aos eventos que ocorrem na vida desse mesmo grupo e a interpretação dos significados dos mesmos para uma 
cultura do grupo. Há, no entanto, debate sobre se esta é uma abordagem ou procedimento de pesquisa (o que é discutido mais adiante).

A pesquisa quantitativa pode ser vista como um método científico (PASCHOARELLI et al., 2015) que se apoia em diferentes técnicas estatísticas para quantificar opiniões e informações para um determinado estudo. Nesse tipo de pesquisa, o pesquisador desenvolve seu trabalho partindo de um plano muito bem estruturado e preestabelecido, formulando hipóteses a respeito do que pretende estudar, com variáveis claramente definidas. É indicada para compreender o raciocínio lógico e todas as informações passíveis de medição sobre as experiências humanas.

As relações entre estas formas de pesquisa podem ser observadas sob perspectiva de objeto de estudo, forma de coleta e análise de dados, interpretação e validação de resultados, o papel do investigador, delineamento da pesquisa e aplicabilidade da pesquisa.

\section{PECULIARIDADES DAS PESQUISAS QUALITATIVAS, QUANTITATIVAS E ETNOGRÁFICAS}

Para Godoy (1995), as pesquisas denominadas qualitativas se centram no estudo e na análise do mundo empírico em seu ambiente natural, valorizandose o contato direto e prolongado ${ }^{4}$ do pesquisador com o objeto de estudo. Triviños (1987) e Godoy (1995) apontam o estudo de caso como procedimento essencial deste tipo de pesquisa caracterizado por um trabalho de campo intensivo, em que os dados são coletados utilizando-se variados equipamentos, como videocassete e gravadores ou, comumente, fazendo-se anotações num bloco de papel. Nesse processo, estruturações teóricas, hipóteses, procedimentos metodológicos não devem obstruir a visão de aspectos essenciais do objeto de pesquisa que representa a totalidade do indivíduo alicerçado ao

\footnotetext{
${ }^{4}$ Existe uma grande discussão em torno da duração de uma etnografia, havendo autores, como Richardson (1994), que sugerem o termo micro etnografia.
} 
princípio da Gestalt ${ }^{5}$ e que não apenas a opinião do pesquisador é relevante, mas de todos os participantes da pesquisa (MAYRING, 2002).

De um modo geral, as características da pesquisa qualitativa, encontradas em Godoy (1995), Hancock (2002), Mayring (2002), Flick (2009), Symon e Cassell (2012), se resumem nos seguintes termos: foco na interpretação e não na quantificação; ênfase na subjetividade; flexibilidade nos processos de pesquisa; maior interesse pelo processo do que pelos resultados; implicação do pesquisador, que exerce influência sobre a situação de pesquisa e também é influenciado por ela; é um método indutivo; a amostra é geralmente pequena; a análise dos dados é interpretativa e descritiva; os resultados são situacionais e limitados ao contexto.

Ainda sobre a pesquisa qualitativa, Hancock (2002), Mayring (2002), Vergara (2005) e Flick (2009) salientam como principais tipos de abordagens a Fenomenologia, a Etnografia, a Teoria Fundamentada em Dados, os Estudos de Caso, a Pesquisa-ação e a Pesquisa Histórica, e relativamente à coleta de dados, destacam-se os seguintes métodos: entrevistas individuais (narrativas e centradas num problema), grupo de discussão, gravações e observação participante.

Em relação à pesquisa quantitativa, Hayati et al. (2006) referem que segue o modelo clássico que defende a ideia da existência, numa dada pesquisa, de uma realidade externa, que pode ser analisada de forma objetiva, em que os resultados podem ser reproduzidos e generalizados, e, por isso, poder se obter verdades universais.

Terrence e Escrivão Filho (2006), Silva et al. (2014) salientam que esta pesquisa só tem sentido quando o problema for muito bem definido e houver informações e teorias complementares sobre o objeto da pesquisa, e ainda se basear em algo observável e cientificamente provado.

Na pesquisa quantitativa, a "explicação de fenômenos" é por meio da coleta de dados, geralmente numéricos, que são analisados por meio de métodos estatísticos e matemáticos; o pesquisador desenvolve seu trabalho

\footnotetext{
${ }^{5}$ Princípio desenvolvido na Alemanha por Max Wertheimer (1880-1943), segundo o qual o comportamento não pode se limitar apenas ao que se pode observar e medir. Todo estímulo é percebido, primeiro, em sua forma mais simples.
} 
partindo de um plano muito bem estruturado e preestabelecido, formulando hipóteses a respeito do que pretende estudar, com variáveis claramente definidas. Busca, portanto, resultados precisos como forma de evitar equívocos na análise e interpretação dos dados, garantindo maior segurança em relação às inferências obtidas (ALIAGA; GUNDERSON, 2002; RICHARDSON, 2008; PASCHOARELLI, et al., 2015).

Silva et al. (2014), ao comentarem que as abordagens quantitativas requerem do pesquisador um extenso conhecimento sobre o que será investigado para que o instrumento de análise seja completo e contemple amplamente as dimensões do objeto de estudo, dão a entender que não existe uma pesquisa puramente quantitativa, existindo relações de complementaridade e de suporte e não mutuamente excludentes.

De um modo geral, Hancock (2002), Vergara (2005), Alves-Mazzotti; Gewandsznajder (2005) destacam as seguintes características para esta abordagem: inferência dedutiva; generalização dos resultados; objetividade da realidade investigada; tamanho da amostra relativamente grande e determinada por métodos estatísticos; utilização de dados representativos de uma determinada população; utilização de questionários estruturados com questões fechadas, testes e checklists, utilização dos tipos de pesquisa correlacional, a survey (levantamento), a experimental e a causal-comparativa.

A abordagem etnográfica consiste essencialmente em uma descrição dos eventos que têm lugar na vida do grupo, com especial consideração para as estruturas sociais, o perfil e a conduta dos sujeitos como membros integrantes do grupo, assim como de suas interpretações e significados da cultura a que fazem parte (WOODS, 1987; FLICK, 2009). Permite, portanto, aproximações e detecções que favorecem a aquisição dos dados nas respectivas fontes, utilizando instrumentos como observação participante, os documentos pessoais, os entrevistados, com o propósito de proceder a investigação de palavras escritas e/ou orais, dados descritos em condutas observáveis dos participantes, de conhecer as pessoas e ter a percepção de como elas desenvolvem suas próprias definições.

De forma geral, López (1999), Richardson (2008) apresentam como características dessa abordagem, nomeadamente: i) Caráter holístico - 
descrever os fenômenos de maneira global em seu contexto natural, aceitando o cenário que encontre e a totalidade como elementos básicos; ii) Condição naturalista - o etnógrafo estuda as pessoas em seu habitat natural. Observa, ouve, fala, anota as histórias de vida; iii) Uso da via indutiva - se apoia nas evidencias para suas conceituações e teorias, na empatia e habilidade geral do investigador para estudar outras culturas; iv) Caráter fenomenológico - os significados se estudam desde o ponto de vista dos agentes sociais; v) Os dados aparecem contextualizados - as observações situam-se dentro de uma perspectiva mais ampla; vi) Livre de juízo de valor - o etnógrafo evita emitir juízos de valor sobre as observações.

O quadro 1 apresenta elementos comparativos das três abordagens metodológicas discutidas aqui.

Quadro 1 - Quadro comparativo das abordagens metodológicas.

\begin{tabular}{|c|c|c|c|}
\hline \multirow{2}{*}{ Características } & \multicolumn{3}{|c|}{ Abordagens } \\
\hline & Qualitativa & Quantitativa & Etnográfica \\
\hline Tipo & Subjetiva & Objetiva & Subjetiva \\
\hline Finalidade & 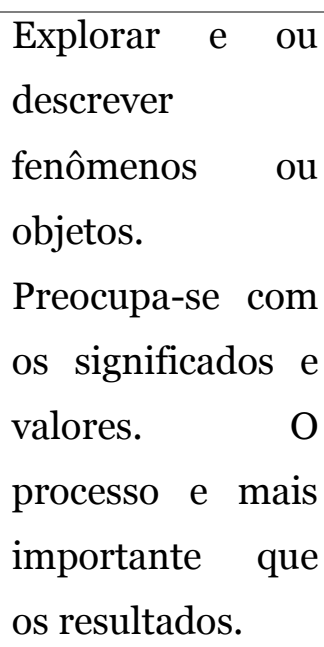 & $\begin{array}{l}\text { Medir, quantificar e ou } \\
\text { comparar opiniões e } \\
\text { resultados. Preocupa-se } \\
\text { em analisar os dados. }\end{array}$ & $\begin{array}{l}\text { Estudo sociocultural, ou } \\
\text { forma de vida da } \\
\text { sociedade, descrevendo as } \\
\text { crenças e práticas do } \\
\text { grupo, mostrando como a } \\
\text { diversidade do grupo ou } \\
\text { comunidade contribuem } \\
\text { para desenvolver a } \\
\text { cultura como um todo } \\
\text { unificado e consistente. }\end{array}$ \\
\hline Amostra & $\begin{array}{l}\text { Número pequeno } \\
\text { de entrevistados. } \\
\text { Todos os } \\
\text { participantes da } \\
\text { pesquisa são } \\
\text { relevantes. }\end{array}$ & $\begin{array}{l}\text { Número maior de } \\
\text { entrevistados que } \\
\text { projetará a população } \\
\text { toda representada. As } \\
\text { amostras são definidas } \\
\text { com base em métodos } \\
\text { estatísticos. }\end{array}$ & $\begin{array}{l}\text { Todos os participantes } \\
\text { são relevantes, mas } \\
\text { existem os chamados } \\
\text { atores-chave que } \\
\text { constituem fontes } \\
\text { primárias, protetores e } \\
\text { guia do investigador. }\end{array}$ \\
\hline
\end{tabular}




\begin{tabular}{|c|c|c|c|}
\hline Questionário & $\begin{array}{l}\text { Segue um roteiro, } \\
\text { grava/anota as } \\
\text { opiniões dos } \\
\text { entrevistados. }\end{array}$ & $\begin{array}{l}\text { Estruturado } r \text { com } \\
\text { perguntas claras } \quad \text { e } \\
\text { objetivas. }\end{array}$ & $\begin{array}{l}\text { Não segue roteiro, } \\
\text { grava/anota as opiniões } \\
\text { dos participantes. }\end{array}$ \\
\hline Entrevistas & $\begin{array}{l}\text { Individual- } \\
\text { Entrevista em } \\
\text { Profundidade } \\
\text { (EP) - conversa } \\
\text { informal Grupo } \\
\text { (bate-papo). } \\
\text { Interação } \\
\text { dinâmica entre o } \\
\text { pesquisador e o } \\
\text { objeto de estudo. }\end{array}$ & $\begin{array}{l}\text { Individuais e seguem } \\
\text { critérios } \\
\text { preestabelecidos como: } \\
\text { sexo, idade, tipo de } \\
\text { atividade, localização } \\
\text { geográfica, etc. } \\
\text { Dificilmente se escuta o } \\
\text { participante após a } \\
\text { coleta de dados. }\end{array}$ & $\begin{array}{l}\text { Não há entrevistas } \\
\text { propriamente ditas, o } \\
\text { pesquisador conversa e } \\
\text { anota as informações dos } \\
\text { participantes } \\
\text { focais). }\end{array}$ \\
\hline $\begin{array}{l}\text { Apresentação } \\
\text { de resultados }\end{array}$ & $\begin{array}{l}\text { Podem ser } \\
\text { expressos através } \\
\text { de transcrições } \\
\text { destacando } \\
\text { opiniões, } \\
\text { comentários e } \\
\text { frases ou } \\
\text { Fotografias, } \\
\text { desenhos, etc. }\end{array}$ & $\begin{array}{l}\text { Deve ser expresso em } \\
\text { tabelas, } \quad \text { gráficos } \\
\text { percentuais, etc. }\end{array}$ & $\begin{array}{l}\text { Podem ser expressos } \\
\text { através de transcrições } \\
\text { destacando } \\
\text { comentários e frases ou } \\
\text { Fotografias, desenhos, } \\
\text { etc. }\end{array}$ \\
\hline $\begin{array}{l}\text { Enfoque } \\
\text { metodológico }\end{array}$ & $\begin{array}{l}\text { Inferência } \\
\text { Indutiva, } \\
\text { Fenomenologia, a } \\
\text { Etnografia, a } \\
\text { Teoria } \\
\text { Fundamentada } \\
\text { em Dados, os } \\
\text { Estudos de Caso, } \\
\text { a Pesquisa-ação e } \\
\text { a Pesquisa } \\
\text { Histórica. }\end{array}$ & $\begin{array}{l}\text { Inferência Dedutiva, } \\
\text { pesquisa correlacional, } \\
\text { a survey } \\
\text { (levantamento), a } \\
\text { experimental e a } \\
\text { causal-comparativa. }\end{array}$ & $\begin{array}{l}\text { Indutivo, } \\
\text { fenomenológico, holístico, } \\
\text { Pesquisa-ação e a } \\
\text { Pesquisa Histórica. }\end{array}$ \\
\hline
\end{tabular}




\begin{tabular}{|c|c|c|c|}
\hline $\begin{array}{l}\text { Postura do } \\
\text { pesquisador }\end{array}$ & $\begin{array}{l}\text { Há aceitação } \\
\text { explícita da } \\
\text { influência de } \\
\text { crenças e valores } \\
\text { sobre a teoria, } \\
\text { sobre a escolha de } \\
\text { tópicos da } \\
\text { pesquisa, sobre o } \\
\text { método e sobre a } \\
\text { interpretação de } \\
\text { resultados. } \\
\text { Possibilidade de } \\
\text { envolvimento } \\
\text { emocional do } \\
\text { pesquisador com } \\
\text { o seu objeto. }\end{array}$ & $\begin{array}{l}\text { Crenças e valores } \\
\text { pessoais não são } \\
\text { considerados fontes de } \\
\text { influência no processo } \\
\text { científico. O foco da } \\
\text { pesquisa e/ou aquilo } \\
\text { que se quer estudar } \\
\text { deve-se basear em algo } \\
\text { observável e que os } \\
\text { enunciados científicos } \\
\text { devem ser passíveis de } \\
\text { serem verificados. }\end{array}$ & $\begin{array}{l}\text { Estuda as pessoas em seu } \\
\text { habitat natural; observa, } \\
\text { ouve, fala, anota as } \\
\text { histórias de vida; evita } \\
\text { emitir juízos de valor } \\
\text { sobre as observações. }\end{array}$ \\
\hline $\begin{array}{l}\text { Métodos de } \\
\text { coleta de } \\
\text { dados }\end{array}$ & $\begin{array}{l}\text { Estudo de caso: } \\
\text { observação } \\
\text { participante, } \\
\text { Gravações, } \\
\text { entrevistas } \\
\text { abertas } \\
\text { semiestruturadas, } \\
\text { grupos focais, } \\
\text { fotografia, } \\
\text { filmagem. }\end{array}$ & $\begin{array}{l}\text { Observação, } \\
\text { experimento e survey } \\
\text { (levantamento). }\end{array}$ & $\begin{array}{lr}\text { Coleta de } & \text { dados } \\
\text { respectivas } & \text { fontes } \\
\text { utilizando os } & \text { principais } \\
\text { instrumentos } & \text { como } \\
\text { interatividade, observação } & \text { os } \\
\text { participante, } & \text { os } \\
\text { entrevistados, } & \text { documentos } \\
\text { documentos oficiais. }\end{array}$ \\
\hline $\begin{array}{l}\text { Métodos de } \\
\text { análise de } \\
\text { dados }\end{array}$ & $\begin{array}{l}\text { Interpretação } \\
\text { utilizando } \\
\text { métodos } \\
\text { hermenêuticos, } \\
\text { análise narrativa, } \\
\text { do discurso, de } \\
\text { documentos. } \\
\text { Relativa falta de } \\
\text { controlo de }\end{array}$ & 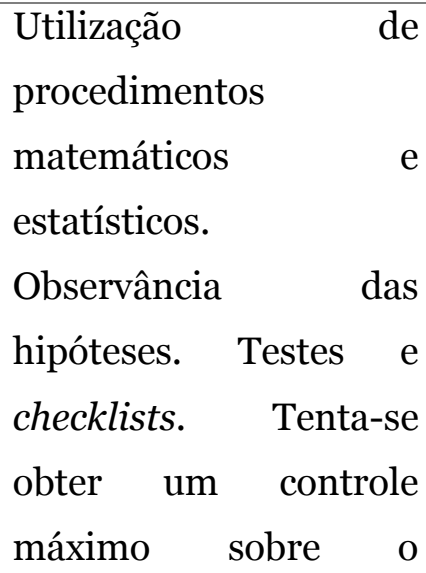 & $\begin{array}{l}\text { Triangulação, descrição } \\
\text { usando citações e relatos } \\
\text { literais na linguagem } \\
\text { empregada r pelos } \\
\text { participantes. Selecionar } \\
\text { com cuidado as } \\
\text { informações } \\
\text { chaves tendo em conta } \\
\text { que suas perspectivas }\end{array}$ \\
\hline
\end{tabular}




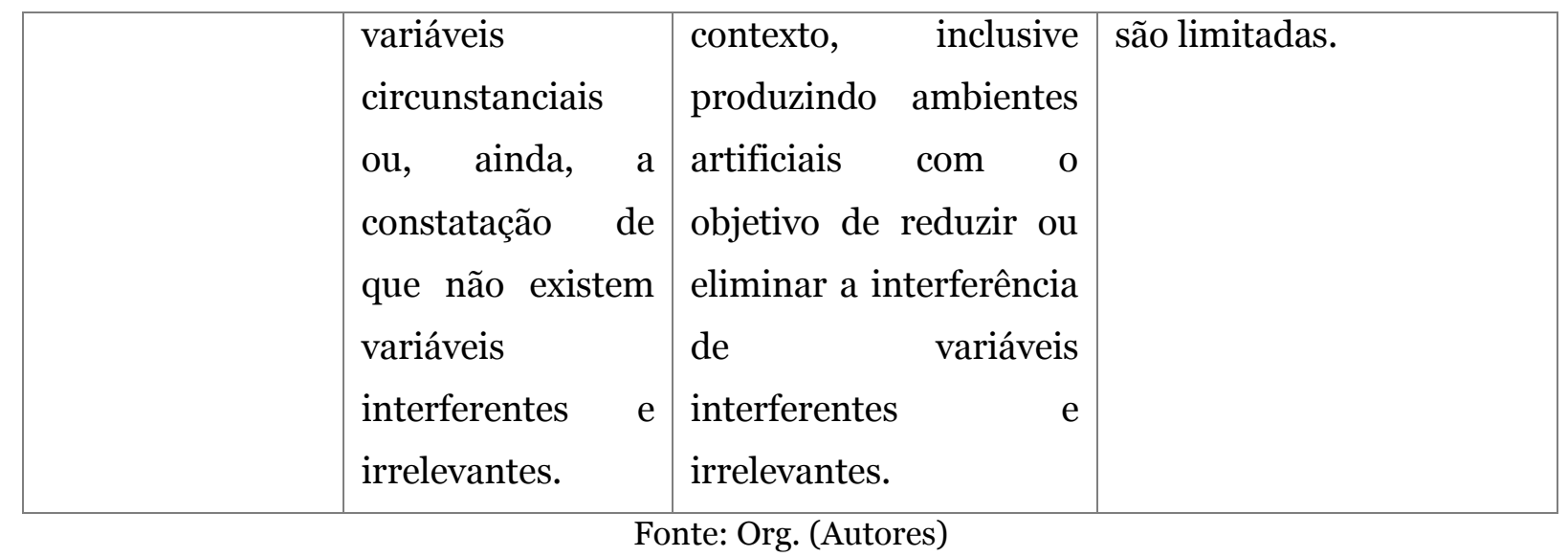

\section{ABORdAgens METOdológicAs NO CAMPO DA PESQUISA DA DINÂMICA DE USO E COBERTURA DA TERRA}

A ciência geográfica, como qualquer outra ciência, passou por mudanças metodológicas ao longo da sua história, face aos desafios que se impunham à geografia. Desses desafios, podemos referir a urbanização acelerada, expansão do capitalismo, industrialização, o planejamento econômico e territorial, que forçaram a transição de uma geografia tradicional (fundamentada no positivismo clássico) cujas análises eram feitas com base na observação, descrição e representação dos fatos, para uma geografia moderna [a Geografia Pragmática e a Geografia Crítica] (PESSÔA, 2012).

Face a essa crise, que não somente afetou as técnicas mas também a linguagem (metodologia), a procura por "novos caminhos" teóricometodológicos permitiu que, em seus trabalhos, o geógrafo retomasse técnicas de pesquisa já utilizadas, como, por exemplo, o trabalho de campo e a observação, e acrescentou outras como a entrevista, a história oral, a pesquisaparticipante, a pesquisa-ação, o estudo de caso, a análise do discurso, o diário de campo (PESSÔA, 2012), como já vinha sugerindo George (1972) sobre a necessidade de a Geografia ser metodologicamente heterogénea, alinhando-se, por um lado, entre as ciências da terra/natureza (mineralogia, geologia, biologia) e, por outro lado, situar-se entre as ciências do homem (sociologia, história). 
Os estudos da paisagem estiveram desde tempos remotos alicerçados em métodos da geografia tradicional (corografia ${ }^{6}$ ). A questão de uso e cobertura de terra está inserida no campo da geografia física, mais precisamente no campo de estudo da paisagem. De acordo com Bertrand (2004), essa questão apresenta múltiplos significados e não deve ser entendida como uma simples adição de elementos geográficos disparatados, mas, sim, como porção do espaço, que resulta da combinação dinâmica, e, portanto, instável de elementos biológicos, físicos, e antrópicos os quais, reagindo dialeticamente entre si, fazem da paisagem um conjunto único e indissociável, em contínua evolução. É por isso que Bertrand (2004) afirma que estudar uma paisagem é a priori apresentar um problema de método.

O conceito de paisagem integra o conceito de espaço visto na perspectiva de Milton Santos (1926-2001). Santos (1999) integra o espaço dentro da paisagem ao afirmar que:

"O espaço é a sociedade... A paisagem existe, através de suas formas, criadas em momentos históricos diferentes, porém coexistindo no momento atual. No espaço, as formas de que compõe a paisagem preenchem, no momento atual, uma função atual, como resposta às necessidades atuais da sociedade." Santos (1999, p. 84).

Sob essa perspectiva, a questão de uso e cobertura da terra está intimamente ligada aos conceitos de paisagem e espaço que, por mais distintos que sejam, na ótica de Santos (1999), são a cara e a coroa de uma mesma moeda - o meio geográfico.

Olhando a Geografia como ciência que estuda as relações entre a sociedade e a natureza, ou por outra, a forma como a sociedade organiza o espaço geográfico ou, ainda, a relação Homem-Natureza, visando melhor explorar e dispor dos recursos da natureza (ANDRADE, 2008), o seu campo de atuação torna-se vasto, não cabendo a reprodução do seu objeto de estudo (o meio geográfico) por meio de uma única abordagem metodológica. Tal como refere Santos (1997), o objeto de estudo da Geografia é formado por um conjunto indissociável, solidário e ao mesmo tempo contraditório, de sistemas

${ }^{6}$ Entendida como a descrição de regiões ou localidades individuais. 
de objetos e sistemas de ações, que devem ser estudados como um quadro único no qual a história tem lugar.

Ainda na ótica de Santos, na análise do espaço, deve-se levar em consideração algumas categorias inerentes: a forma, a função, a estrutura e o processo, sendo que as formas representam elementos (áreas agrícolas, estradas) localizáveis em determinadas posições geográficas, e a este respeito chama atenção à necessidade de entender a função de cada uma dessas formas e estabelecer relações entre elas no contexto da descrição da paisagem, pois entende que as formas são criadas para atender a determinados objetivos (SANTOS, 1997). O autor salienta ainda que as formas devem ser registadas pelo fato de não possuírem a mesma idade; elas são criadas em diferentes épocas, por conseguinte, o espaço tem uma história, tem uma vida. Portanto, existe um processo de formação e transformação do espaço.

A questão da cobertura da terra denota a categorização física, química ou biológica (biofísico) da superfície terrestre e da subsuperfície imediatamente a esta, por exemplo, pastagem, floresta ou concreto, e o uso da terra está relacionado com a maneira como os atributos biofísicos da terra são manipulados e a intenção subjacente a essa manipulação muitas vezes associada à agropecuária, recreação ou vida urbana (MEYER; TURNER, 1992). É influenciado por dois grupos distintos de fatores: os biofísicos (clima, topografia, temperatura, tipo de solo, vegetação, águas superficiais, umidade e fauna) e os sociais (organização socioeconômica cultural e institucional, população, tecnologia e mudanças políticas), sendo estes últimos os mais responsáveis pelas mudanças. Contudo, não devem ser vistos de forma isolada, mas interligados a outros numa perspectiva temporal e espacial (BRIASSOULIS, 2000).

Lambin et al. (2001) referem que as mudanças no uso e cobertura da terra são tão profundas que, quando agregados de forma global, podem afetar de forma significativa os aspectos essenciais do funcionamento dos sistemas terrestres. Este fato torna o estudo da dinâmica de uso e cobertura de terra extremamente importante e seu estudo envolve tanto a pesquisa de escritório bem como de campo, voltadas para a interpretação, análise e registro de 
observações da paisagem, referentes aos tipos de uso e cobertura da terra, para fins de sua classificação e espacialização através de cartas.

Sob esta perspectiva, a pesquisa quantitativa seria mais adequada para este estudo. Entretanto, quando George (1972) discute a questão do visível e do invisível no entendimento da paisagem, a opção pela pesquisa quantitativa já não se afigura adequada de forma exclusiva. Segundo o autor, o comportamento normal da observação, que constitui o primeiro passo de qualquer procedimento geográfico, consiste em propor problemas que deverão ser resolvidos por meio da explicação, sendo que parte desses problemas está relacionada aos dados que escapam ao alcance da observação, principalmente quando se quer tratar de dados pertencentes ao passado e que só se pode observar os efeitos.

Para George (1972), o visível é atingido pela observação, o invisível apenas através de métodos apropriados à sua natureza diferenciados, por conseguinte, na medida em que o invisível é diversificado. Dessa relação, percebe-se que o visível é referente à paisagem e o invisível aos processos formadores e transformadores da paisagem, que são considerados dinâmicos e instáveis com marco temporal e espacial e daí a necessidade de encontrar o entendimento do invisível baseado na pesquisa qualitativa.

$\mathrm{Na}$ tentativa de desvendar o visível, é comum o recurso a documentos que fixam a imagem de tudo que é acessível à observação a que George (1972) designa imagem direta e derivada. Na ótica desse autor, estas duas imagens se complementam na medida em que a direta, embora seja exaustiva no que se refere ao que se pode ver, não introduz nenhuma hierarquia de valores, e a derivada é seletiva e sistemática permitindo a ponderação dos elementos e sua categorização.

\section{DESAFIOS NO LEVANTAMENTO DE USO E COBERTURA DE TERRA EM MOÇAMBIQUE}

Em Moçambique, o levantamento de uso e cobertura de terra está, atualmente, sob responsabilidade do Ministério da Terra, Ambiente e Desenvolvimento Rural (MITADER), através da Direção Nacional de Terras 
(DINAT), Direção Nacional de Florestas (DNF) e o Centro Nacional de Cartografia e Teledetecção (CENACARTA). É responsabilidade dessas instituições relatar o estado de arte concernente ao uso e cobertura de terras por meio de inventários florestais e mapeamentos sistemáticos. Até o momento, já se realizaram três inventários, em 1994, 2007 e 2017, utilizando-se metodologias distintas ${ }^{7}$.

Com estes dados, percebe-se, por um lado, a variação em termos de periodicidade da realização dos inventários, que se justifica por insuficiências financeiras, técnicas e metodológicas. As formas de ocupação (ordenamento) de terras são outro fator a ter em conta.

Em Moçambique, as zonas rurais representam 90\% do território nacional, com aproximadamente 70\% da população vivendo nessas zonas, com hábitos e costumes característicos aliados ao fraco ou mesmo imperceptível ordenamento territorial. Por isso, é comum encontrar situações de múltiplos usos numa determinada cobertura e, na maioria dos casos, pouco expressivos e agravado pela não observância dos planos de uso de terra. O tipo de agricultura praticada pelas comunidades rurais é predominantemente itinerante/sequeiro e as áreas cobertas por esse tipo de agricultura, na sua maioria (cerca de 95\% das áreas de cultivo), não ultrapassam dois (02) hectares. A excessiva ocupação das terras agrícolas com culturas alimentares básicas (milho, mandioca) em áreas muito pequenas possibilita a formação de extensas paisagens agropecuárias indistintas que são frequentemente entremeadas por uma vegetação savânica nativa (RONQUIM et al., 2013).

Por outro lado, devido à urbanização não efetiva em vilas e cidades, caracterizadas por habitações dispersas, cobertas com materiais diversificados (laje, zinco, caniço, telha de fibrocimento, palha, vias de acesso em terra batida (sem pavimento), é comum confundir, no processo de interpretação das imagens, as classes de áreas urbanas e solo exposto induzindo a uma descrição da paisagem equivocada.

\footnotetext{
${ }^{7}$ De acordo com Sitoe et al. (2012) o primeiro inventário utilizou imagens de satélite e fotografias aéreas para estimar a cobertura vegetal, e o segundo apenas fez uma comparação de imagens de satélite para as províncias de Manica e Maputo.
} 
A figura 1 ilustra uma paisagem (cidade/vila de Cuamba na província de Niassa, norte de Moçambique) na qual se pode observar os arranjos espaciais dos elementos da paisagem.

Figura 1. Arranjo espacial dos elementos da paisagem (vila de Cuamba) vistas sob diferentes escalas em uma imagem satélite e a partir de fotografias.

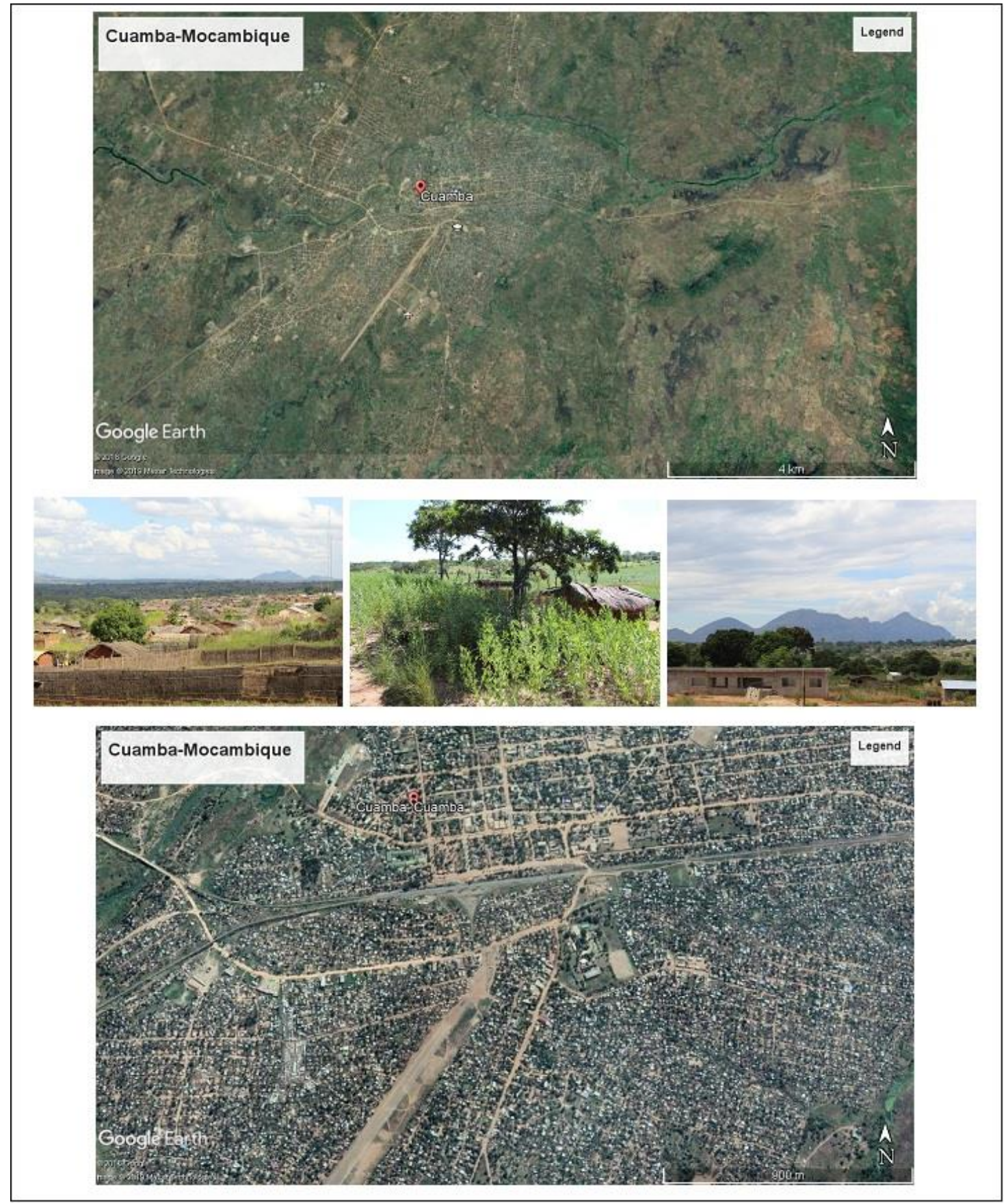

Fonte: Imagem (Google Earth, 2017), fotografias (autores, 2020). 
Os usos acima apresentados são difíceis de identificar em imagens de satélite de média resolução (Landsat, Sentinel) que, muitas vezes, são recomendadas para este tipo de mapeamento por agregarem vantagens, a destacar o livre acesso (Zhu et al., 2018; BARBOSA, C.C.F.; NOVO, E.M.L.M.; MARTINS, 2019).

Esses fatos, associados às limitações dos métodos de classificação de imagens e a constrangimentos de natureza técnica, educacional e institucional, dificultam o processo de interpretação e consequente levantamento de uso e cobertura de terra. Para contornar a situação, convém a permanência do pesquisador no campo por períodos longos devido à necessidade de extrair as amostras de todos usos e integrá-las aos diferentes métodos de classificação. As dificuldades aqui apresentadas surgem também quando se pretende realizar uma análise espacial e temporal da dinâmica de uso e cobertura de terra, que é, muitas vezes, realizado recorrendo a abordagens quantitativas.

As práticas culturais e políticas nas comunidades locais interferem muito nos trabalhos de campo. No âmbito da realização de trabalhos de campo, além de dialogar com o responsável que superintende a área de terras, que geralmente é agente político, é imprescindível estabelecer contatos com as comunidades locais através de seus líderes, os quais devem estar em concordância com o trabalho pretendido, uma vez que pode haver restrições no acesso a determinadas áreas (áreas sagradas), e na socialização com os membros da comunidade. A articulação desse relacionamento com a comunidade é facilmente estabelecida com foco na abordagem qualitativa.

Os fatos apresentados tornam difícil obter mapas muito precisos e de qualidade através de técnicas supervisionadas de classificação, e quase que impossível por meio de técnicas não supervisionadas. Os trabalhos de Tuzine (2011), Macarringue et al. (2015), Mazalo (2018) são alguns exemplos de trabalhos de mapeamento de uso e cobertura de terra em que se obteve exatidão global entre 61,3 e $76 \%$.

No estudo da dinâmica do uso e cobertura de terra em Moçambique, pode se estabelecer duas etapas distintas: a descritiva e a comparativa.

A primeira está mais voltada para a caracterização da paisagem, das formas de uso e cobertura da terra, das relações entre o uso e cobertura da terra. 
Estando o uso ligado ao que Milton Santos chama de espaço, evidenciará as práticas culturais da comunidade local. Esse momento poderá ser alcançado recorrendo à pesquisa histórica, documental, estudo de caso, correlacional, bibliográfica, fenomenológica inseridas nas abordagens qualitativa e quantitativa com recurso à coleta e análise de dados numéricos e não numéricos em campo e no gabinete e grupos de discussão.

A segunda está geralmente associada à dinâmica espacial e temporal das alterações da paisagem mais voltada à análise das alterações de uso e cobertura de terra ao longo da história, tendo como base algumas referências como, por exemplo, dados de referência nacional. Nesta fase, objetiva-se saber o quanto de alteração ocorreu na área de estudo nos diversos momentos da história, em que formas (usos e cobertura) ocorreram maiores alterações, quais foram as prováveis causas dessas alterações.

Para essa fase, além das visitas de campo, será necessário analisar documentos históricos como imagens orbitais do passado e do presente e fontes bibliográficas, conversar com as comunidades na perspectiva de perceber as forças motoras das mudanças e confrontar os usos passados visíveis em imagens satélites que são a base da classificação. Nas visitas de campo, pode-se recorrer à observação, registos fotográficos e levantamento de coordenadas de feições, os quais serão úteis na calibração e validação de dados orbitais.

Outro instrumento de validação de resultados pode ser a comparação dos resultados obtidos com os dados de referência dos levantamentos já realizados em Moçambique. A análise de dados será por meio de métodos estatísticos e também o método descritivo e interpretativo, sendo que os dados são processados em laboratório.

Se o estudo da dinâmica de uso e cobertura de terra estiver mais voltado para a descrição das variações espaciais dos padrões de uso e cobertura de terra do que entender realmente por que essas variações ocorrem e qual é o sentimento da comunidade ao articular esses usos/variações, recomenda-se o foco nas abordagens quantitativas. Mas, se o estudo transcender a visão das comunidades na articulação dos usos, as abordagens qualitativas são mais adequadas. 
O quadro 2 ilustra algumas atividades que podem ser desenvolvidas no âmbito do levantamento do uso e cobertura de terra e seu enquadramento em abordagens metodológicas.

Quadro 2 - Enquadramento metodológico das ações do levantamento de uso e cobertura da terra.

\begin{tabular}{|c|c|c|}
\hline Tarefa & Atividades relacionadas & $\begin{array}{l}\text { Enquadramento } \\
\text { metodológico }\end{array}$ \\
\hline \multirow{3}{*}{$\begin{array}{l}\text { Caracterização da } \\
\text { paisagem: clima, } \\
\text { solos, relevo, } \\
\text { geologia, vegetação, } \\
\text { uso de terra }\end{array}$} & $\begin{array}{l}\text { Análise documental } \\
\text { bibliográficas, base de dados e } \\
\text { imagens satélites); }\end{array}$ & Qualitativo/quantitativo \\
\hline & $\begin{array}{l}\text { Coleta de dados em campo (registo } \\
\text { fotográfico, observação; }\end{array}$ & Qualitativo/quantitativo \\
\hline & $\begin{array}{l}\text { Redimensionamento da área de } \\
\text { estudo (distritos) }\end{array}$ & Qualitativo/quantitativo \\
\hline \multirow{2}{*}{$\begin{array}{l}\text { Relações entre uso e } \\
\text { cobertura da terra }\end{array}$} & Análise documental; & Qualitativo/quantitativo \\
\hline & Observação em campo; & Qualitativo/quantitativo \\
\hline \multirow{5}{*}{$\begin{array}{l}\text { Mapeamento e } \\
\text { análise da dinâmica } \\
\text { de uso e cobertura } \\
\text { de terra }\end{array}$} & $\begin{array}{l}\text { Análise e interpretação de imagens } \\
\text { orbitais em laboratório e com base } \\
\text { em métodos estatísticos }\end{array}$ & Quantitativo \\
\hline & $\begin{array}{lcc}\text { Comparação com os } & \text { dados de } \\
\text { referência } & \text { de } & \text { outros } \\
\text { levantamentos/outros métodos; }\end{array}$ & Quantitativo \\
\hline & $\begin{array}{l}\text { Levantamento de dados em campo } \\
\text { (coordenadas, registo fotográfico) }\end{array}$ & Qualitativo/quantitativo \\
\hline & $\begin{array}{l}\text { Descrição das formas de uso e } \\
\text { cobertura de terra; }\end{array}$ & Qualitativo/quantitativo \\
\hline & $\begin{array}{l}\text { Separação e quantificação das áreas } \\
\text { abrangidas por determinadas formas } \\
\text { de uso e cobertura de terra. }\end{array}$ & Quantitativo \\
\hline
\end{tabular}

Fonte: Org. (Autores) 


\section{CONSIDERAÇÕES FINAIS}

O presente ensaio, além da discussão sobre as abordagens metodológicas da pesquisa científica, permitiu analisar o direcionamento metodológico no estudo da dinâmica de uso e cobertura de terra, especificamente no contexto de Moçambique.

Com base nesse olhar e nas atividades que podem ser desenvolvidas no levantamento de uso e cobertura de terra, verificou-se que ambas as abordagens metodológicas (qualitativa e quantitativa) são aplicáveis em vários momentos da pesquisa.

Concluiu-se que é necessário que se observem, nomeadamente, o objetivo e o objeto pretendidos na realização de cada atividade por forma a adequar a uma abordagem específica, ou seja, para cada etapa, é possível identificar uma abordagem metodológica que melhor responde aos objetivos e ao objeto. O desenvolvimento de uma pesquisa é um processo dinâmico e, por conta disso, questões circunstanciais ligadas ao objeto de pesquisa podem ocorrer exigindo a alternância das abordagens metodológicas.

Considerando a complexidade e os desafios (sobretudo de natureza metodológica) que caracterizam os estudos sobre o uso e cobertura da terra em contextos como o moçambicano, é fundamental que os governantes envolvam pesquisadores da área, com a qualificação necessária, para melhor orientação na condução dos estudos desta natureza.

\section{AGRADECIMENTOS}

$\mathrm{O}$ primeiro autor agradece ao $\mathrm{CNPq}$ pelos recursos financeiros e ao Rafael Straforini pelo incentivo para a realização da pesquisa.

\section{REFERÊNCIAS BIBLIOGRÁFICAS}

ALIAGA, Martha; GUNDERSON, Brenda. Interactive Statistics. New Jersey: Prentice Hall, 2002.

ALVES-MAZZOTTI, Alda J.; GEWANDSZNAJDER, Fernando. O método nas ciências naturais e sociais. São Paulo: Pioneira Thomson Learning, p. 203, 2004. 
ANDRADE, Manuel. C. Geografia, ciência da sociedade: uma introdução à análise do pensamento geográfico. Recife: UFPE, 2008.

Barbosa, C.C.F.; Novo, E.M.L.M.; Martins, V.S.. Introdução ao

Sensoriamento Remoto de Sistemas Aquáticos: princípios e aplicações. $1^{\text {a }}$ edição. Instituto Nacional de Pesquisas Espaciais. São José dos Campos. 161p. 2019.

BERTRAND, George. Paisagem e geografia física global. Esboço metodológico. R. RA'E GA, Curitiba, Editora UFPR, n. 8, p. 141-152, 2004.

BRIASSOULIS, H. Analysis of land use change: theoretical and modeling approaches. In: WebBook of Regional Science Ed. S Loveridge, Regional Research Institute, West Virginia University, Morgantown, WV, 2000. Disponível em: http://www.rri.wvu.edu/WebBook/Briassoulis/contents.htm, Acesso em: 20 mar. 2013.

FETTERMAN, David M. Ethnograpy. Step by steps. Londres: Sage, 1989.

FLICK, Uwe. Introdução à pesquisa qualitativa, Tradução de Joice Elias Costa, $3^{\mathrm{a}}$. Ed., Porto Alegre, Artmed, p. 405, 2009.

FREITAS, Wesley R. S.; JABBOUR, Charbel J. C. Utilizando estudo de caso(s) como estratégia de pesquisa qualitativa: Boas práticas e sugestões. Estudo \& Debate, Lajeado, v. 18, n. 2, p. 07-22, 2011.

GAMBOA, Silvio A. S. Epistemologia da pesquisa em educação: estruturas lógicas e tendências metodológicas. São Paulo. 1987. 228f. Tese (Doutorado em Educação) - Faculdade de Educação, Universidade Estadual de Campinas, Campinas-SP, 1987.

GEORGE, Pierre. Os Métodos da Geografia. São Paulo: Difusão Europeia do Livro, 1972.

GODOY, Irilda S. Introdução à pesquisa qualitativa e suas possibilidades: Uma revisão histórica dos principais autores e obras que refletem esta metodologia de pesquisa em Ciências Sociais. Revista de Administração de Empresas, São Paulo, v. 35, n. 2, p. 57-63 Mar./Abr. 1995.

GUNTHER, Hartmut. Pesquisa Qualitativa Versus Pesquisa Quantitativa: Esta é a Questão? Psicologia: Teoria e Pesquisa, Brasília, Vol. 22 n. 2, pp. 201-210, Mai-Ago 2006.

HANCOCK, Beverley. Trent Focus for Research and Development in Primary Health Care: An Introduction to Qualitative Research. Nottingham: Trent Focus, 2002. 
HAYATI, Dariush; KARAMI, Ezatollah; \& SLEE, Bill. Combining qualitative and quantitative methods in the measurement of rural poverty. Social Indicators Research, v.75, p.361-394, Springer, 2006.

HEGENBERG, Leonidas. Explicações científicas: introdução à filosofia da ciência. Editora da Universidade de São Paulo. 1976.

LAMBIN, E. et al. The causes of land-use and land-cover change: moving beyond the myths. Global Environmental Change 11 p. 261-269. 2001.

LÓPEZ, Graciela, L. O método etnográfico como um paradigma científico e sua aplicação na pesquisa. Rev. Textura Canoas, n. 1, p. 45-50, 1999.

MACARRINGUE, Lucrêncio S.; MATULE, Euclides D.; MATUMBUANE, Nercílio L. Integração da dimensão espacial na planificação de uso de terra ao nível distrital - estudo de caso de Boane. Anais... XVII Simpósio Brasileiro de Sensoriamento Remoto - SBSR, João Pessoa-PB, Brasil, 25 a 29 de abril de 2015 .

MAYRING, Ph. Einführung in die qualitative Sozialforschung [Introdução à pesquisa social qualitativa]. ( $5^{\mathrm{a}}$ ed.). Weinheim: Beltz. 2002.

MAZALO, Etelvina da Conceição José. Cartografia de ocupação da terra com imagens Landsat para o distrito de Marracuene - Moçambique. Dissertação (Mestrado em Ciencia e Sistemas de Informação Geográfica). Nova Information Management School. 2018. 83f. Disponível em:

https://run.unl.pt/bitstream/10362/48103/1/TSIGo128_vers\%C3\%A30\%20fin al.pdf. Acesso em: 13 jul. 2020.

MEYER W.; TURNER B. L. Human Population Growth and Global LandUse/Cover Changes. Annu. Rev. Ecol. Syst. 23: p. 39-61. 1992.

OLIVEIRA, Maria Marly. Como fazer pesquisa qualitativa. Petrópolis, Vozes, 2007.

PASCHOARELLI, Luis, C.; MEDOLA, Fausto, O.; BONFIM, Gabriel, H., C., Características Qualitativas, Quantitativas e Quali-quantitativas de Abordagens Científicas: estudos de caso na subárea do Design Ergonômico. Revista de Design, Tecnologia e Sociedade, pp. 65-78, 2(1), 2015.

PESSÔA, Vera L. S. GEOGRAFIA E PESQUISA QUALITATIVA: um olhar sobre o processo investigativo. Geo UERJ - Ano 14, no . 23, v. 1, p. 4-18, 2012.

RICHARDSON, Roberto J. Pesquisa Social - Métodos e Técnicas. $3^{\text {a }}$ edição. São Paulo, Atlas. 334 p. 2008.

RONQUIM Carlos C.; RIBEIRO, Fernando; BOLFE, Édson L.; TOSTO Sérgio. Uso de Geotecnologias para avaliação da agropecuária de Moçambique. 
Anais... XVI Simpósio Brasileiro de Sensoriamento Remoto - SBSR, Foz do Iguaçu, PR, Brasil, 13 a 18 de abril de 2013.

SÁ-SILVA, Jackson Ronie; ALMEIDA Cristóvão, Domingos \& GUINDANI, Joel Felipe. Pesquisa documental: pistas teóricas e metodológicas. Revista Brasileira de História \& Ciências Sociais. Ano I - Número I - Julho de 2009.

SANTOS, Milton. A natureza do espaço: espaço e tempo, razão e emoção. 3. ed. São Paulo: Hucitec, 1999.

A natureza do espaço: técnica e tempo, razão e emoção. 2. ed. São Paulo: Hucitec, 1997.

SILVA, Dirceu da; LOPES, Evandro L. \& BRAGA JUNIOR, Sérgio S., Pesquisa quantitativa: elementos, paradigmas e definições. Revista de Gestão e Secretariado - GeSec, São Paulo, v. 5, n. 1, p 01-18, jan./abr. 2014.

SITOE, A.; SALOMÃO, A.; WERTZ-KANOUNNIKOFF, S. O contexto de REDD+ em Moçambique: Causas, actores e instituições. Publicação Ocasional 76. CIFOR, Bogor, Indonesia. 2012.

SYMON, Gillian \& CASSELL, Catherine. Qualitative Organizational Research: Core Methods and Current Challenges. London: Sage Publications, 2012.

TERRENCE, Ana C. F.; ESCRIVÃO FILHO, Edmundo. Abordagem quantitativa, qualitativa e a utilização da pesquisa-ação nos estudos organizacionais. In. ENCONTRO NACIONAL DE ENGENHARIA DE PRODUÇÃO, Fortaleza. Anais... p. 1-9. 2006.

THEÓPHILO, Carlos R.; IUDÍCIBUS, Sérgio. As novas abordagens metodológicas na pesquisa em contabilidade gerencial, Anais... Cruzando Fronteras: Tendencias de Contabilidad Directiva para el Siglo XXI, León, España, 4 al 6 de julio, 2001.

TRIVIÑOS, Augusto Nibaldo Silva. Introdução à pesquisa em ciências sociais: a pesquisa qualitativa em educação. São Paulo: Atlas, 1987.

TUZINE, Mário S. Mapeamento da cobertura e uso da terra a partir de imagens ikonos na floresta de inhamacari, província de manica Moçambique. Dissertação (mestrado em Engenharia Florestal). Setor de Ciências Agrárias, Universidade Federal do Paraná, Curitiba (PR), 2011. 91f. Disponível em: https://acervodigital.ufpr.br/bitstream/handle/1884/26458/d563_o732M.pdf?sequence=1\&isAllowed=y. Acesso em: 13 jul. 2020.

VERGARA, Sylvia C., Método de pesquisa em administração. São Paulo: Atlas, 2005. 
VOSS, Chris; TSIKRIKTSIS, Nikos; FROHLICH, Mark. Case research in operations management. International Journal Of Operations \& Production Management, v. 22, n. 2, p. 195-219, 2002.

WOODS, Peter. La escuela por dentro: la etnografia en la investigación educativa. Barcelona: Paidós, 1987.

YIN Robert K. Estudo de caso: planejamento e métodos. 3 ed. Porto Alegre: Bookman, 2005.

ZHU, L. et al. A Review: Remote Sensing Sensors. Multi-purposeful Application of Geospatial Data. 2018.

Recebido em 8 de novembro de 2019 Aceito em 23 de julho de 2020 